Ainsworth, G. C. (1952). J. gen. Microbiol. 7, 358-361.

\title{
The Incidence of Air-borne Cladosporium Spores in the London Region
}

\author{
By G. C. AINSWORTH \\ Department of Botany, University College, Exeter
}

SUMMARY : Spore trapping by the Petri dish method showed the incidence of airborne Cladosporium herbarum spores, which fluctuated markedly from day to day, to be similar in Central London and in an outer suburb throughout the year.

Although it was in Europe that the ability of air-borne fungus spores to act as allergens was first recognized, the most detailed surveys of the fungus spore content of the air have been made in the United States. Increasing attention is, however, being paid to this topic elsewhere, and in Britain the Asthma and Allergy Unit at Cardiff is now supplementing studies on the incidence of airborne pollen with investigations on the occurrence of fungus spores. Reports have already appeared on the incidence of Alternaria spores (Hyde \& Williams, 1946) and of fungus spores in general (Hyde \& Williams, 1949).

In 1946, during a search for new antibiotics, it was decided to follow the clue provided by Fleming's discovery of penicillin and to sample the fungus spores present in the atmosphere, but by design, and this note summarizes certain data obtained by the systematic exposure of plates in and around London between August 1946 and September 1948.

\section{METHODS}

As a result of experiments with different media and with different periods of exposure at different times of day of varying numbers of plates freely exposed to the air and variously protected from rain, it was decided to sample by exposing six $9 \mathrm{~cm}$. Petri dishes of potato glucose agar for $5 \mathrm{~min}$., protected from rain in an apparatus, of similar type and dimensions to that described by Hyde \& Williams (1945), set up $10 \mathrm{ft}$. from the ground in a grass field well away from the laboratory buildings. Exposures were made at 12 noon on 6 days each week and the plates were subsequently incubated at $25^{\circ}$, the number of colonies developing being counted on or about the 7 th day. The colonies were divided into two categories, 'bacteria and yeasts' and 'fungi'.

In addition to the exposure of plates, a microscope slide smeared with glycerine jelly was exposed in the tower for $24 \mathrm{hr}$. (noon-noon) every day. Rain and the daily maximum and minimum temperatures were recorded, and the direction of the wind at the time of exposure of the plates was noted.

The exposures were made at Sutton, Surrey, situated about 15 miles southwest of London at an altitude of $250 \mathrm{ft}$. 


\section{RESULTS}

\section{Effect of falling rain}

In the course of preliminary experiments a series of thirty-six exposures was made during August 1946. On thirty occasions the weather was fine, on six rain was falling and the number of fungi developing on plates exposed during rain greatly exceeded that during dry periods (ar. wet, 189; ar. dry, 43). On one occasion when the plates were exposed during a sharp thunder storm the number of colonies developing on the six plates was 565 , the highest recorded during the survey. The results suggested that this increase in the spore content of the air was only temporary and that the number soon fell to 'normal' when the rain stopped, but the increase during rain was unexpected and did not appear to have been noted by modern observers.

The results obtained in 1872 by $D$. D. Cunningham, during what may be regarded as the first scientific study of the spore content of the air by the 'vertical slide' method, show a similar effect in that at the Presidency Jail, Calcutta, and at Alipore, more spores were trapped on days for which rain was recorded than on dry days; the averages for the $\mathbf{2 4} \mathrm{hr}$. periods being: Presidency Jail, dry 145, wet 165; Alipore, dry 132, wet 197 (Cunningham, 1873; data in Tables 1 and 2 ).

A possible explanation of this effect is that the rain-drops wash spores out of the upper air and increase the turbulence of the air near the ground. No relation was noted between periods of wet weather and the daily fluctuations in the numbers of spores trapped (see below).

\section{Effect of the time of day}

During the same series of experiments, plates were exposed at 10 a.m., 12 noon, 2 p.m. and 4 p.m. on 6 fine days in August 1946 when the average number of spores trapped at the different times were $40 \cdot 8,39 \cdot 3,40 \cdot 2$ and $\mathbf{5 4 \cdot 7}$, respectively. This suggested an increase during the afternoon, probably due to a greater turbulence of the air, and it was for this reason that noon was selected for routine sampling.

\section{Daily fluctuation in the number of Cladosporium colonies}

It was not possible to identify all the fungi on all the plates and $C$. herbarum, a species known to be involved in allergic disorders, is the only fungus for which an accurate record is available for the whole series. C. herbarum, an unspecialized and ubiquitous saprophyte, accounted for approximately half of the 'fungus' colonies and this is in accord with the findings of Hyde \& Williams (1949) for Cardiff. C. herbarum was also the species most frequently recorded from the air by Blackaller (1950) in Mexico and by Ambler \& Vernon (1951) in New Zealand.

The daily incidence of Cladosporium during October-November 1946 and January-February 1947 is summarized in Fig. 1. The shape of the graph is very similar to that for all 'fungi' during the same period (see Ainsworth, 
1952, fig. 5), and is characterized by constant fluctuations. The reasons for these fluctuations are obscure. There would appear to be no obvious correlation with periods of wet weather. There is, however, a general fall in numbers during the winter and particularly during periods of snow. The only day on which the plates remained sterile during the 5 min. exposure was on 24 February 1947 when snow covered the ground.

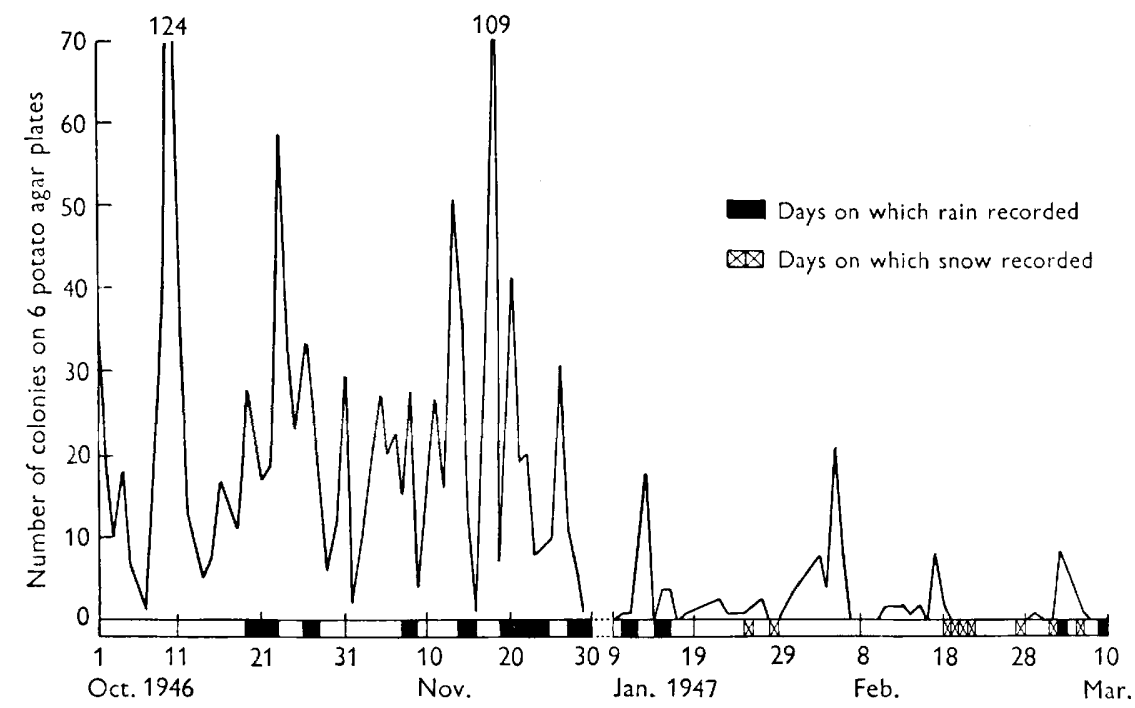

Fig. 1. Daily incidence of C. herbarum spores trapped at Sutton, Surrey.

\section{Comparison of the incidence of Cladosporium spores in central London and in an outer suburb}

When the total numbers of fungi trapped were correlated with the direction of the wind the average number of colonies per exposure was: N. (NW., N., NE.), 29·4; S. (SW., S., SE.) 45·7; E. (NE., E., SE.), 34•4; W. (NW., W., SW.), $39 \cdot 0$. This suggested that fewer colonies developed when the wind had traversed the metropolitan area than when it had blown over the open country to the south and west, and so in the following year an opportunity was taken to compare central London with Sutton.

The method was as described except that five malt agar plates were exposed at each sampling (the sixth being kept unopened as a control) and the exposures were made only once a week, simultaneously at 12 noon on the roof of the London School of Hygiene and Tropical Medicine (London, W.C. 1) and through the skylight of a house in Sutton a few hundred yards from the site of the 1946-7 exposures.

As in the earlier series, $C$. herbarum was the only fungus consistently identified throughout the experiment, and the average monthly incidence of this species at the two stations is summarized in Fig. 2. The two curves show very close agreement and suggest that 'local' conditions have little effect 
on the general fungus spore content of the outdoor air. Both curves also illustrate the seasonal cycle in the incidence of Cladosporium spores which has a maximum in the summer and a minimum during the winter months as noted by Hyde \& Williams (1949).

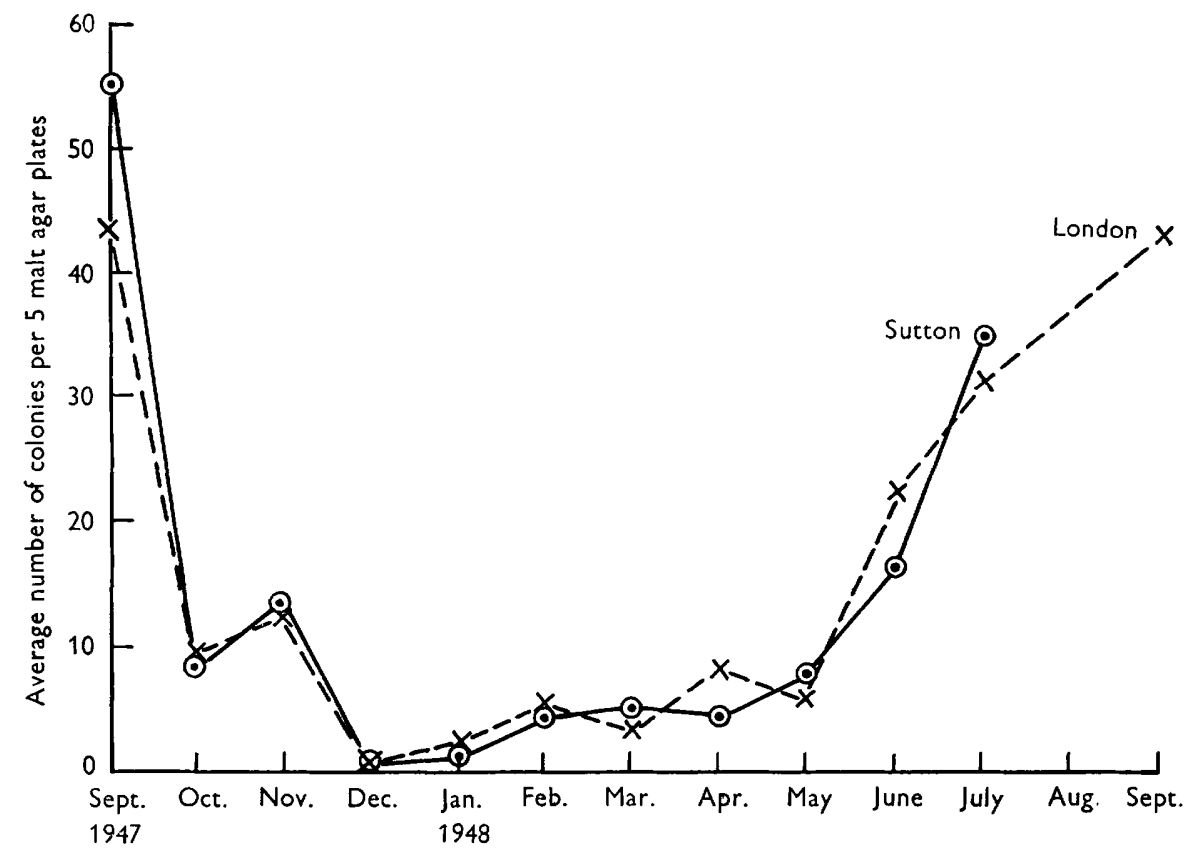

Fig. 2. Average monthly incidence during 1947-48 of C. herbarum spores trapped at Sutton, Surrey and in Central London.

Acknowledgement is made to Dr J. W. Trevan, F.R.S., of the Wellcome Research Laboratories, Beckenham, for permission to publish certain data, to the Wellcome Trustees for financial assistance, to Mrs M. Beech for allowing access to the skylight at 3 Grange Road, Sutton, and to my wife for exposing plates.

\section{REFERENCES}

Ainsworth, G. C. (1952). Medical Mycology. An Introduction to its Problems. London: Sir Isaac Pitman and Sons Ltd.

Ambler, M. P. \& Vernon, T. R. (1951). Airborne mould spores. A survey of the atmospheric spore load in the Auckland City and suburban area. N.Z. J. Sci. Tech. A, 33, 79.

Blackaller, F. A. (1950). Estudio de los hongos atmosféricos en la ciudad de Guadalajara, Jalisco. Medicina, Méx. 30, 111.

Cunningham, D. D. (1873). Microscopic Examinations of Air. Calcutta.

Hyde, H. A. \& Williams, D. A. (1945). Studies in atmospheric pollen. II. Diurnal variation in incidence of grass pollen. Nerv Phytol. 44, 83.

Hyde, H. A. \& Williams, D. A. (1946). A daily census of Alternaria spores caught from the atmosphere at Cardiff in 1942 and 1943. Trans. Brit. mycol. Soc. $29,78$.

Hyde, H. A. \& Williams, D. A. (1949). A census of mould spores in the atmosphere. Nature, Lond. 164, 668.

(Received 30 April 1952) 